\title{
Avaliação da degradação proteica da fibra capilar por ação de xampus
}

\author{
Camila Helena Ferreira Cuelho* Iuri de França Bonilha* Gizele \\ Scotti do Canto**
}

Resumo: Este estudo teve como objetivo comparar o potencial de degradação proteica da fibra capilar de um xampu magistral frente a um produto comercial. Como amostra, utilizou-se mechas de cabelo castanho adulto isento de procedimento químico. As mechas foram limpas com solvente orgânico para remover a gordura e realizaram-se ensaios de fricção em duplicata para cada xampu, simulando 0 processo de lavagem dos cabelos. Retiraram-se alíquotas de $0,1 \mathrm{~mL}$ da água de lavagem a cada 2 ciclos de lavagens até 0 total de 14 ciclos e quantificou-se a perda proteica pelo método do ácido bicinconínico (BCA). A deteç̧ão foi realizada por espectrofotometria em $562 \mathrm{~nm}$. Considerando a lavagem diária dos cabelos, houve uma perda proteica anual de $6,4824 \mathrm{mg} / \mathrm{g}$ de cabelo lavado com 0 xampu magistral e de $5,9605 \mathrm{mg} / \mathrm{g}$ utilizando o xampu comercial. Observou-se que a diferença da perda proteica do cabelo lavado com os dois xampus foi estatisticamente significativa.

Descritores: Desnaturação Proteica, Cabelo, Preparações para Cabelo.

\section{Evaluation of protein degradation of hair fiber by shampoos action}

Abstract: This study aimed to compare the potential of protein degradation of the hair fiber of a magistral shampoo against a commercial product. As a sample, we used adult brown hair tresses free of chemical procedure. Rovings were cleaned with organic solvent to remove fat and friction assays were performed in duplicates for each shampoo, simulating the process of hair washing. Withdrew aliquots of $0.1 \mathrm{~mL}$ of wash water every two washing cycles until 14 cycles and quantified protein loss by the bicinchoninic acid method (BCA). Detection was carried out by spectrophotometry at $562 \mathrm{~nm}$. Considering the daily washing of hair, were annual protein loss of $6.4824 \mathrm{mg} / \mathrm{g}$ hair washed with the magistral shampoo and $5.9605 \mathrm{mg} / \mathrm{g}$ using the commercial shampoo. It was observed that the difference in protein loss from hair washed with two shampoos was statistically significant.

Descriptors: Protein Denaturation, Hair, Hair Preparations.

\footnotetext{
* Graduada em Farmácia pela Universidade Federal de Santa Maria (UFSM), Santa Maria, RS, Brasil.

**Doutora em Ciências Farmacêuticas pela Universidade Federal do Rio Grande do Sul (UFRGS), Porto Algre, RS, Brasil.
} 


\section{Introdução}

Atualmente o cabelo possui uma grande importância econômica e social. Os pêlos, em geral, não exercem nenhuma função vital em nosso organismo. Entretanto, o cabelo, do ponto de vista social, aumenta a auto-estima; enquadra as pessoas em um determinado grupo social, cultura ou etnia; além do apelo estético e sexual. Diariamente o cabelo é danificado, seja pela exposição solar; poluição; água de mar ou piscina; tratamentos químicos e o próprio ato de lavar com xampu e enxugar os cabelos. ${ }^{1}$

O fio de cabelo é um polímero proteico formado por cerca de $80 \%$ de a-queratina, um tipo específico de queratina, e outros materiais não queratinosos. Esta proteína possui uma grande quantidade do aminoácido cistina que, devido à alta presença de enxofre, possui uma forte resistência ao ataque químico. ${ }^{1-3}$ Morfologicamente, o cabelo é dividido em três camadas: cutícula, córtex e medula. ${ }^{3}$

A cutícula é responsável pela proteção das células do córtex, pelas propriedades superficiais (brilho, atrito, penteabilidade, desembaraçamento) e regula a entrada e saída de água. $O$ córtex, que constitui a maior parte da massa do fio, é responsável pelas propriedades elásticas e resistência mecânica; e contém grânulos de melanina que variam em tipo, quantidade e tamanho, sendo responsáveis pela cor e fotoproteção do cabelo. A medula corresponde à região central da fibra capilar e, por representar uma pequena porcentagem de todo o fio, contribui de forma insignificante nas propriedades mecânicas da fibra capilar. 1,2,4,5

Os xampus são produtos cuja finalidade é promover a limpeza dos cabelos. No entanto, as expectativas dos consumidores vão além deste simples conceito e variam de acordo com 0 tipo e a condição dos cabelos, condições fisiológicas do couro cabeludo, estação, idade, estilo de vida e hábitos de cuidados. Estes esperam que, além da limpeza, o xampu torne o cabelo mais brilhante, macio, condicionado, protegido, reparado, com vitalidade, volume, facilmente penteado e manuseado. ${ }^{1,6}$

A formulação básica de um xampu é composta por um agente de limpeza (tensoativo), estabilizador de espuma, espessante, corretivo do $\mathrm{pH}$, sequestrante, conservante, corante, essência ou fragrância e água. Os tensoativos contribuem com a maior parte das propriedades do produto como aparência, espuma, grau de irritação, limpeza e condicionamento do cabelo. Entretanto, o uso destes tensoativos está associado à presença de toxicidade no organismo humano e animal, devido às modificações das estruturas proteicas (desnaturação) e disfunção das enzimas, bem como alterações nas membranas fosfolipídicas. .,8 $^{-1}$

Todavia, há estudos na literatura que comprovam o potencial de degradação proteica e os danos que alguns tensoativos e o processo de lavagem causam à fibra capilar. ${ }^{3,4}$

Sendo assim, como foram analisados os danos que apenas os tensoativos causam aos cabelos, o presente trabalho teve como objetivos comparar o perfil da perda proteica da fibra capilar por ação de formulações de xampu magistral e comercial; analisar a metodologia empregada comparando-a com outros métodos e comparar a influência da formulação no perfil de degradação proteica. 


\section{Metodologia}

Para a realização deste experimento, foram utilizadas mechas de cabelo castanho adulto isento de procedimento químico (cabelo virgem) medindo cerca de $20 \mathrm{~cm}$ de comprimento. As amostras de xampus utilizadas foram: Formulação magistral contendo os seguintes componentes: lauril éter sulfato de sódio, dietanolamida de ácido graxo de coco, diestearato de polietilenoglicol 6000 , solução de ácido cítrico a $30 \%$, cloreto de sódio, solução conservante com propilenoglicol, essência, imidazolidinil uréia, lanolina etoxilada, extrato vegetal de babosa, corante, EDTA e água; e Formulação comercial contendo os seguintes componentes: lauril sulfato de sódio, lauril éter sulfato de sódio, diestearato de etilenoglicol, dimeticona, citrato de sódio, cocoamida monoetanolamina, xileno sulfonato de sódio, cocoamidopropil betaína, perfume, cloreto de sódio, ácido cítrico, benzoato de sódio, poliquatérnio 76, EDTA, pantenol, pantenil etil éter, metilisotiazolinona, metilcloroisotiazolinona e água.

Primeiramente, as mechas foram lavadas com $300 \mathrm{~mL}$ de éter etílico em extrator de Soxhlet sob refluxo por 8 horas. 0 objetivo desta lavagem foi remover gordura e/ou resíduos de tratamentos anteriores com o propósito de que estes não interferissem no experimento. Após a lavagem, as mechas foram armazenadas em um vidro de relógio e envolvidas com papel alumínio para que se evitasse a deposição de poeira. ${ }^{4,9}$

Para a determinação da perda proteica do cabelo e a confecção da curva padrão, foi empregado o método do ácido bicinconínico (BCA), utilizado para a detecção e quantificação de proteínas totais em $562 \mathrm{~nm}$. Nesta metodologia, utilizou-se o kit comercial do método juntamente com a albumina de soro bovino (ASB) como proteína padrão., ${ }^{4,10}$

Conforme especifica o kit do método, para cada amostra (tubo) são necessários $2 \mathrm{~mL}$ de reagente de trabalho (RT). A seguinte fórmula foi empregada para calcular o volume (V) de RT a ser preparado para a confecção da curva padrão e para o tratamento das mechas:

a) $\left(n^{0}\right.$. padrões ou $n^{0}$. amostras) $\times$ (replicatas) $\times$ (volume de RT por tubo) $=V_{\text {TOTAL DE RT }}$;

b) Curva padrão $\rightarrow$ (5 padrões ou tubos) $\times(2$ replicatas) $\times(2 \mathrm{~mL})=20 \mathrm{~mL}+2 \mathrm{~mL}=22$ $\mathrm{mL}$;

c) Mechas $\rightarrow$ (7 amostras ou tubos) $\times$ (1 replicata) $\times(2 \mathrm{~mL})=14 \mathrm{~mL}+2 \mathrm{~mL}=16 \mathrm{~mL}$.

Em cada dia do tratamento das mechas e do preparo da curva padrão, foi preparado 2 $\mathrm{mL}$ a mais do RT para que este volume fosse usado como o branco para a leitura no espectrofotômetro. No cálculo do volume de RT utilizado no tratamento das mechas consta apenas 1 replicata porque cada replicata foi realizada em dias diferentes.

Como a preparação da curva padrão e o tratamento das mechas em cada replicata foram feitos em dias diferentes, preparou-se o RT em separado para cada procedimento no dia da realização do mesmo. Para preparar o RT, utilizaram-se os reagentes A e B do kit. 0 Reagente $\mathrm{A}$ contém carbonato de sódio, bicarbonato de sódio, ácido bicinconínico e tartarato de sódio em hidróxido de sódio $0,1 \mathrm{~mol} / \mathrm{L}$; e o Reagente $B$ contém $4 \%$ de sulfato cúprico.

O RT foi preparado misturando-se 50 partes do Reagente A com 1 parte do Reagente B (proporção 50:1, Reagente $A: B$ ). Portanto, para a curva padrão preparou-se o RT misturandose (em um béquer de $50 \mathrm{~mL}$ ) $22 \mathrm{~mL}$ do Reagente $A$ com $0,44 \mathrm{~mL}$ do Reagente $B$; e para a determinação da perda proteica das mechas, o RT foi preparado misturando-se (em um béquer de $50 \mathrm{~mL}) 16 \mathrm{~mL}$ do Reagente $A$ com $0,32 \mathrm{~mL}$ do Reagente $B$.

Na preparação da curva padrão, foi necessário fazer uma solução de tampão fosfato

Rev. Saúde (Santa Maria), Santa Maria, v.39, n.2, p.109-120, Jul./Dez.2013. Cuelho, C.H.F.; Bonilha, I.F.; Canto, G.S. SSN 2236.5843 
salino (PBS) para ser utilizado como diluente nas diluições da ASB. Preparou-se $10 \mathrm{~mL}$ das soluções de fosfato de sódio monobásico $0,2 \mathrm{~mol} / \mathrm{L}\left(\mathrm{NaH}_{2} \mathrm{PO}_{4}\right)$ e fosfato de sódio dibásico heptahidratado $0,2 \mathrm{~mol} / \mathrm{L}\left(\mathrm{Na}_{2} \mathrm{HPO}_{4} \cdot 7 \mathrm{H}_{2} \mathrm{O}\right)$ para preparar $20 \mathrm{~mL}$ de solução de tampão fosfato de sódio $0,1 \mathrm{~mol} / \mathrm{L}$ de $\mathrm{pH}$ 7,2. Apartir desta solução, foi preparado $10 \mathrm{~mL}$ de PBS. Nas diluições, foi utilizada uma ampola de ASB de concentração $2 \mathrm{mg} / \mathrm{mL}$. A Tabela 1 apresenta 0 esquema de diluições da ASB para a obtenção das soluções para a construção da curva padrão, conforme especificado no kit do método.

Tabela 1 - Esquema de diluições de ASB para concentrações de 5 a $250 \mu \mathrm{g} / \mathrm{mL}$.

\begin{tabular}{cccc}
\hline Tubos & $\mathrm{V}_{\mathrm{PBS}}$ & $\mathrm{V}_{\mathrm{ASB}}$ (fonte) & Sol. Padrão $_{\text {ASB }}$ \\
\hline 1 & $700 \mu \mathrm{L}$ & $100 \mu \mathrm{L}$ (ampola) & $250 \mu \mathrm{g} / \mathrm{mL}$ \\
2 & $400 \mu \mathrm{L}$ & $400 \mu \mathrm{L}$ (tubo 1) & $125 \mu \mathrm{g} / \mathrm{mL}$ \\
3 & $450 \mu \mathrm{L}$ & $300 \mu \mathrm{L}$ (tubo 2) & $50 \mu \mathrm{g} / \mathrm{mL}$ \\
4 & $400 \mu \mathrm{L}$ & $400 \mu \mathrm{L}$ (tubo 3) & $25 \mu \mathrm{g} / \mathrm{mL}$ \\
5 & $400 \mu \mathrm{L}$ & $100 \mu \mathrm{L}$ (tubo 4) & $5 \mu \mathrm{g} / \mathrm{mL}$
\end{tabular}

PBS = tampão fosfato salino.

$A S B=$ albumina de soro bovino.

Após o preparo das diluições, retirou-se de cada tubo de diluição de ASB (tubos 1 a 5) uma alíquota de $0,1 \mathrm{~mL}$ para outro tubo de ensaio e acrescentou-se $2 \mathrm{~mL}$ de RT, misturandose bem (em duplicata). Os tubos foram tampados com parafilme, incubados em banho-maria a $60{ }^{\circ} \mathrm{C}$ por 30 minutos, resfriados a temperatura ambiente por 2 minutos e lidos em espectrofotômetro a $562 \mathrm{~nm}$. Utilizou-se o RT para zerar o equipamento e as amostras foram lidas em até 10 minutos após serem retiradas do banho, sendo o tempo em que a taxa de desenvolvimento da cor púrpura da reação é lenta. ${ }^{10}$

A curva padrão e a equação da reta foram geradas através de um software, obtendo-se uma curva linear nas concentrações da faixa de trabalho (5 a $250 \mu \mathrm{g} / \mathrm{mL}$ ).

No tratamento das mechas de cabelo foram realizados ensaios de friç̧ão para que se simulasse o processo de lavagem diária dos cabelos, utilizando uma massa de 0,5 $\mathrm{g}$ de cabelo para cada xampu (comercial e magistral). Aplicou-se às amostras sequências de 14 ciclos de lavagens.

Em cada ciclo de lavagem as mechas foram molhadas em um béquer de $250 \mathrm{~mL}$ contendo $100 \mathrm{~mL}$ de água destilada. Agitou-se com um bastão de vidro por 3 minutos; retirouse 0 excesso de água da mecha escorrendo pela parede do frasco; colocou-se a mecha em um cadinho e adicionou-se $0,25 \mathrm{~mL}$ do xampu (comercial e magistral); friccionou-se as mechas com as mãos por 2 minutos com luvas de látex até a formação de espuma; mergulhou-se a mecha em outro béquer de $250 \mathrm{~mL}$ com $50 \mathrm{~mL}$ de água destilada (água de lavagem) sob agitação com bastão de vidro por 3 minutos, sendo utilizado o mesmo frasco em todos os ciclos de lavagens para conservar as proteínas liberadas nos outros ciclos. Por fim, removeu-se o excesso de espuma da mecha com água destilada em outro béquer e iniciou-se novamente o ciclo descrito com a mesma mecha.

Foram retiradas alíquotas de $0,1 \mathrm{~mL}$ da água de lavagem a cada 2 ciclos de lavagens

Saúde (Santa Maria), v.39, n.2, p.109-120, 2013. Avaliação da degradação proteica da fibra capilar por ação de xampus até 0 total de 14 ciclos (7 tubos) e quantificada a perda proteica. Os ensaios foram realizados em duplicata para cada xampu. Os tubos de ensaio foram identificados pelos números 2, 4, 6, 
8, 10, 12 e 14 (correspondentes aos ciclos de lavagens). Após, adicionou-se em cada tubo 2 $\mathrm{mL}$ do RT, misturou-se bem, e estes foram tampados com parafilme e incubados em banhomaria à $60^{\circ} \mathrm{C}$ por 30 minutos. Passado este tempo, os tubos foram resfriados à temperatura ambiente por 2 minutos e realizou-se a leitura em espectrofotômetro a $562 \mathrm{~nm}$ em até 10 minutos após os mesmos serem retirados do banho-maria. Utilizou-se como branco o RT.

Para calcular a concentração proteica perdida pelas mechas na água de lavagem, usouse a equação da reta (curva padrão) e os valores das respectivas absorvâncias médias de cada ciclo. A partir dos valores da perda proteica na água de lavagem, foi calculado as respectivas concentrações de perda proteica diretamente na fibra capilar, em miligramas de proteína por grama de cabelo.

A análise estatística dos resultados obtidos foi realizada utilizando o teste $t$ de Student para amostras pareadas.

\section{Resultados e Discussão}

0 método do ácido bicinconínico (BCA) combina a redução do íon cúprico $\left(\mathrm{Cu}^{2+}\right)$ a íon cuproso $\left(\mathrm{Cu}^{1+}\right)$ pela proteína em meio alcalino (reação do biureto) com a detecção colorimétrica altamente sensível e seletiva do cátion cuproso usando um único reagente contendo ácido bicinconínico. A reação de coloração púrpura produzida no ensaio ocorre devido à quelação de duas moléculas de BCA com um íon cuproso. ${ }^{10}$

A ASB pode ser utilizada como proteína padrão, devido esta apresentar cerca de $23 \%$ em massa dos aminoácidos cistina (e seu derivado cisteína), triptofano e tirosina; ao passo que a queratina capilar possui de 20 a $25 \%$. Sendo assim, a utilização da ASB para a determinação da curva padrão torna-se eficiente, levando em consideração que as quantidades de proteína medidas são em massa e, teoricamente, a correlação de proteínas entre a ASB e 0 cabelo são muito próximas. ${ }^{4}$

A Tabela 2 apresenta os resultados das absorvâncias (Abs) e seus respectivos desvios padrão, utilizados na elaboração da curva padrão.

\begin{tabular}{|c|c|c|c|c|}
\hline Sol. Padrão $_{\text {ASB }}(\mu \mathrm{g} / \mathrm{mL})$ & $\mathrm{Abs}_{\text {replicata } 1}$ & $\mathrm{Abs}_{\text {replicata } 2}$ & $A b s_{\text {média }}$ & Desvio padrão \\
\hline 5 & 0,116 & 0,112 & 0,114 & 0,003 \\
\hline 25 & 0,196 & 0,186 & 0,191 & 0,007 \\
\hline 50 & 0,314 & 0,311 & 0,313 & 0,002 \\
\hline 125 & 0,631 & 0,604 & 0,618 & 0,019 \\
\hline 250 & 1,120 & 1,115 & 1,118 & 0,004 \\
\hline
\end{tabular}

Na Figura 1 está ilustrada a curva padrão juntamente com a equação da reta, a qual foi gerada utilizando-se um software. 


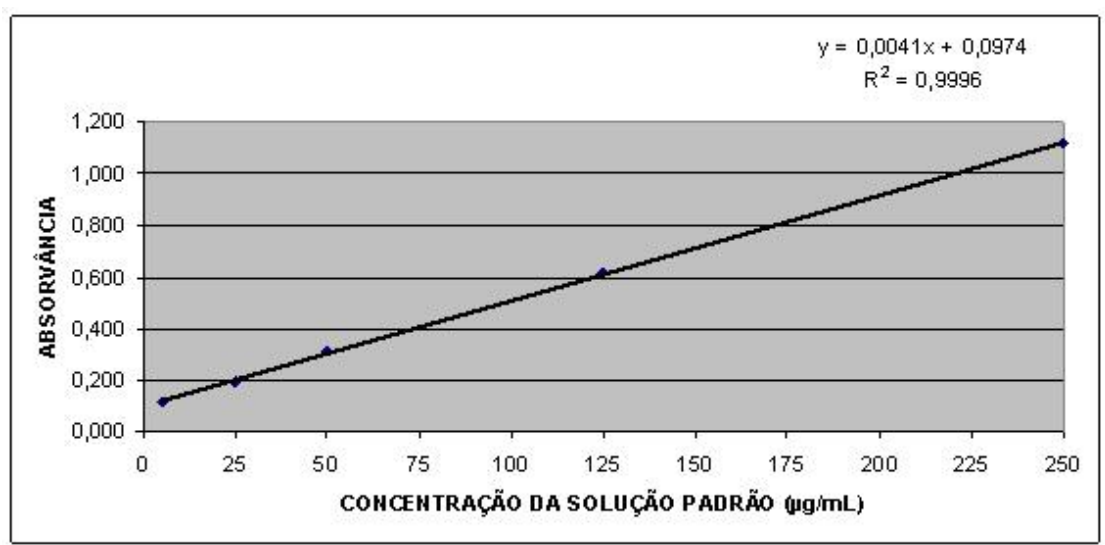

Figura 1 - Curva padrão e equação da reta das soluções padrão de ASB a 562 nm.

Há duas possibilidades de lavagem do cabelo, uma utilizando surfactantes como o lauril sulfato de sódio (LSS) ou lauril éter sulfato de sódio (LESS); e outra utilizando solventes orgânicos voláteis como éter etílico, etanol e misturas de metanol com clorofórmio. ${ }^{4,9}$ Optouse pela utilização de solvente orgânico devido este não interferir na estrutura proteica do cabelo ${ }^{4}$ e também devido aos surfactantes estarem presentes nas formulações de xampu utilizadas no experimento.

O uso do etanol como solvente de lavagem não é recomendado para este experimento devido este possuir alto ponto de ebulição $\left(78^{\circ} \mathrm{C}\right)$, podendo, assim, promover a degradação do cabelo. Utilizando o método de extração por Soxhlet, foi observado que as temperaturas de extração (remoção da gordura e outros resíduos das mechas) são próximas do ponto de ebulição dos solventes utilizados. Sendo assim, a temperatura de extração do éter etílico é muito próxima da temperatura fisiológica. Com isso, selecionou-se o éter etílico como 0 solvente orgânico de lavagem, pois este possui baixo ponto de ebulição $\left(34^{\circ} \mathrm{C}\right) .{ }^{9}$

Os cálculos realizados para a determinação da concentração de perda proteica capilar na água de lavagem e nas mechas estão exemplificados a seguir:

a) cálculo da concentração de perda proteica capilar na água de lavagem;

$\mathrm{Abs}_{\text {média }}=0,216$ (ciclo $2-x a m p u$ comercial)

$y=0,0041 x+0,0974$ (equação da reta - curva padrão)

$y=$ absorvâncias

$x=$ concentração da perda proteica na água de lavagem em $\mu \mathrm{g} / \mathrm{mL}$

$0,216=0,0041 x+0,0974$

$x=28,92 \mu \mathrm{g} / \mathrm{mL}$

b) cálculo da concentração de perda proteica capilar nas mechas.

$$
\begin{array}{r}
28,92 \mu \mathrm{g}=0,02892 \mathrm{mg}-1 \mathrm{~mL}-0,5 \mathrm{~g} \text { de cabelo } \\
57,84 \mu \mathrm{g}=0,05784 \mathrm{mg}-1 \mathrm{~g} \text { de cabelo }
\end{array}
$$

Saúde (Santa Maria), v.39, n.2, p.109-120, 2013. Avaliação da degradação proteica da fibra capilar por ação de xampus

Após o tratamento das mechas de cabelo com o xampu magistral e a avaliação da perda proteica através do método BCA utilizando a equação da reta, obtiveram-se os seguintes valores de absorvâncias e perda proteica apresentados na Tabela 3. 
Tabela 3 - Absorvâncias, perda proteica média e desvio padrão pela lavagem do cabelo com o xampu magistral.

\begin{tabular}{ccccc}
\hline Ciclos & $\mathrm{Abs}_{\text {média }}$ & $\mathrm{PP}_{\text {média }}$ água de lavagem & $\mathrm{PP}_{\text {média }}$ mechas & Desvio padrão \\
\hline 2 & 0,229 & $32,09 \mu \mathrm{g} / \mathrm{mL}$ & $0,06418 \mathrm{mg} / \mathrm{g}$ & 0,01553 \\
4 & 0,284 & $45,51 \mu \mathrm{g} / \mathrm{mL}$ & $0,09102 \mathrm{mg} / \mathrm{g}$ & 0,01414 \\
6 & 0,332 & $57,22 \mu \mathrm{g} / \mathrm{mL}$ & $0,11444 \mathrm{mg} / \mathrm{g}$ & 0,01551 \\
8 & 0,428 & $80,63 \mu \mathrm{g} / \mathrm{mL}$ & $0,16126 \mathrm{mg} / \mathrm{g}$ & 0,01793 \\
10 & 0,464 & $89,41 \mu \mathrm{g} / \mathrm{mL}$ & $0,17882 \mathrm{mg} / \mathrm{g}$ & 0,01174 \\
12 & 0,530 & $105,51 \mu \mathrm{g} / \mathrm{mL}$ & $0,21102 \mathrm{mg} / \mathrm{g}$ & 0,01277 \\
14 & 0,607 & $124,29 \mu \mathrm{g} / \mathrm{mL}$ & $0,24858 \mathrm{mg} / \mathrm{g}$ & 0,0376 \\
\hline $\mathrm{PP}=$ perda proteica & & &
\end{tabular}

Com o tratamento do cabelo com o xampu comercial, obtiveram-se também os valores das absorvâncias e perda proteica na água de lavagem e nas mechas, conforme ilustrado na Tabela 4 a seguir.

Tabela 4 - Absorvâncias, perda proteica média e desvio padrão pela lavagem do cabelo com o xampu comercial.

\begin{tabular}{ccccc}
\hline Ciclos & $\mathrm{Abs}_{\text {média }}$ & $\mathrm{PP}_{\text {média }}$ água de lavagem & $\mathrm{PP}_{\text {média }}$ mechas & Desvio padrão \\
\hline 2 & 0,216 & $28,92 \mu \mathrm{g} / \mathrm{mL}$ & $0,05784 \mathrm{mg} / \mathrm{g}$ & 0,00552 \\
4 & 0,270 & $42,09 \mu \mathrm{g} / \mathrm{mL}$ & $0,08418 \mathrm{mg} / \mathrm{g}$ & 0,02001 \\
6 & 0,325 & $55,51 \mu \mathrm{g} / \mathrm{mL}$ & $0,11102 \mathrm{mg} / \mathrm{g}$ & 0,02104 \\
8 & 0,376 & $67,95 \mu \mathrm{g} / \mathrm{mL}$ & $0,1359 \mathrm{mg} / \mathrm{g}$ & 0,02174 \\
10 & 0,431 & $81,36 \mu \mathrm{g} / \mathrm{mL}$ & $0,16272 \mathrm{mg} / \mathrm{g}$ & 0,02243 \\
12 & 0,479 & $93,07 \mu \mathrm{g} / \mathrm{mL}$ & $0,18614 \mathrm{mg} / \mathrm{g}$ & 0,02208 \\
14 & 0,566 & $114,29 \mu \mathrm{g} / \mathrm{mL}$ & $0,22858 \mathrm{mg} / \mathrm{g}$ & 0,02208 \\
\hline
\end{tabular}

A Figura 2 mostra a representação gráfica da perda proteica do cabelo pelo tratamento com os xampus magistral e comercial juntamente com os respectivos desvios padrão em cada ciclo de lavagem.

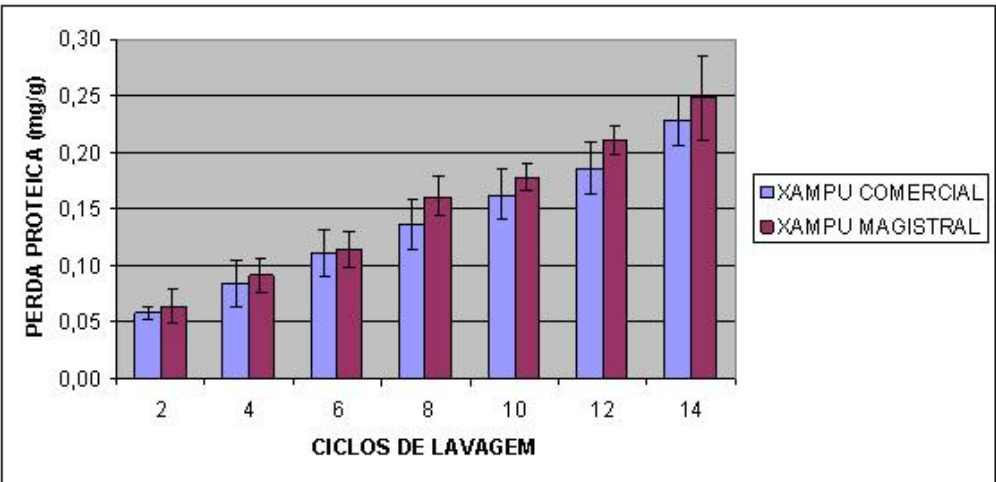

Figura 2 - Perda proteica do cabelo e desvios padrão pelo tratamento com os xampus magistral e comercial em 14 ciclos de lavagem.
Rev. Saúde (Santa Maria), Santa Maria, v.39, n.2, p.109-120, Jul./Dez.2013.

Cuelho, C.H.F. Bonitha, IF. Canto, GS 
Pela análise dos dados, devem-se enfatizar alguns detalhes do experimento. Como foi utilizado o mesmo frasco de água de lavagem em todos os ciclos de tratamentos com cada xampu, considera-se que os valores de perda proteica em cada ciclo seja um acúmulo de proteínas dos ciclos anteriores. Portanto, para calcular a média da perda proteica em cada ciclo, dividiu-se o valor da perda proteica após os 14 ciclos pelo número de ciclos realizados. A seguir, estão demonstrados os cálculos das médias de perda proteica por ciclo de lavagem no tratamento com os dois xampus:

a) média da perda proteica por ciclo de lavagem no tratamento com o xampu magistral;

$0,24858 \mathrm{mg} / \mathrm{g}$ (perda proteica após 14 ciclos) $\div 14$ ciclos $=0,01776 \mathrm{mg} / \mathrm{g}$

b) média da perda proteica por ciclo de lavagem no tratamento com o xampu comercial.

$0,22858 \mathrm{mg} / \mathrm{g}$ (perda proteica após 14 ciclos) $\div 14$ ciclos $=0,01633 \mathrm{mg} / \mathrm{g}$

Considerando que as pessoas lavem os cabelos todos os dias, haveria uma perda proteica anual de $6,4824 \mathrm{mg} / \mathrm{g}$ com o tratamento utilizando o xampu magistral e de 5,9605 $\mathrm{mg} / \mathrm{g}$ utilizando o xampu comercial. Os valores representam uma média, devendo-se considerar, também, as condições em que o experimento foi realizado como, por exemplo, 3 minutos de molhagem dos cabelos; 2 minutos de fricção com o xampu e 3 minutos de enxágue.

Nos ensaios de fricção com solução de LSS $10 \%$ realizados por Wagner, ${ }^{4}$ houve uma perda proteica de aproximadamente $35 \mathrm{mg} / \mathrm{g}$ após 120 ciclos de lavagens (correspondente a 4 meses de banhos diários). Deste modo, em um ano, a perda equivale a cerca de $105 \mathrm{mg} / \mathrm{g}$ de cabelo. 0 procedimento adotado nos ensaios de friç̧ão deste estudo foram os mesmos utilizados neste experimento. No entanto, a metodologia de determinação da perda proteica utilizada foi o método de Lowry ${ }^{11} \mathrm{e}$, no presente estudo, foi utilizado o método BCA.

Estudos envolvendo a comparação entre os métodos de Lowry e BCA mostram que estes possuem resultados comparáveis. Entretanto, os valores discrepantes encontrados nestes ensaios podem ser devido ao padrão proteico utilizado (albumina de soro bovino), que pode responder de forma diferente com os reagentes específicos de cada método. ${ }^{12}$ Apesar disso, outro estudo de comparação de métodos sugere que o método BCA fornece os resultados mais consistentes, como na determinação de proteínas totais no leite humano, utilizando a albumina de soro humano como padrão. ${ }^{13}$ Outro estudo de revisão mostrou que 0 método BCA tem a vantagem de ser mais simples no preparo dos reagentes, sendo tão sensível quanto o método de Lowry e, também, relativamente rápido. ${ }^{14}$

Assim, com relação à metodologia aplicada, os resultados do experimento realizado por Wagner $^{4}$ podem ser comparados aos resultados deste estudo. Todavia, deve-se levar em consideração que neste procedimento ${ }^{4}$ os cabelos foram tratados com uma solução de LSS $10 \%$ nos ensaios de friç̧ão; enquanto que, no presente estudo, utilizou-se formulações completas de xampus, contendo associações de LSS e LESS como tensoativo principal.

Há relatos na literatura de outros procedimentos abrasivos que podem promover danos

Saúde (Santa Maria), v.39, n.2, p.109-120, 2013. Avaliação da degradação proteica da fibra capilar por ação de xampus ISSN 2236-5834 aos cabelos, como secar com a toalha, pentear e escovar. ${ }^{15} \mathrm{Um}$ fator que também influencia na perda proteica é a temperatura. Wagner ${ }^{4}$ realizou estudos de imersão das mechas em 
água, solução de LSS e microemulsão de silicone nas temperaturas de 4,40 e $70^{\circ} \mathrm{C}$. Neste estudo, observou-se um aumento da degradação proteica com o aumento da temperatura. Isto se explica pelo fato de que a temperatura aumenta a velocidade de difusão de substâncias para o interior da fibra, aumentando o intumescimento do material não queratinoso e facilitando a extração do material proteico. Deve-se considerar que, no presente estudo, não foi avaliado a influência da temperatura na perda proteica; sendo que a temperatura média da água utilizada nos ensaios de fricção foi de aproximadamente $20^{\circ} \mathrm{C}$.

Um agente físico que também causa danos aos cabelos é a radiação solar, provocando a fotodegradação capilar. Esta exposição da fibra capilar à radiação solar provoca 0 branqueamento, devido à oxidação da melanina através de radicais livres, e 0 comprometimento da queratina. 0 efeito mais danoso da radiação solar é a oxidação da cistina a ácido cisteico, que modifica suas propriedades mecânicas. A exposição aos raios ultravioleta (UV) provoca mudanças consideráveis na estrutura da queratina, incluindo a fotooxidação dos aminoácidos e ácidos graxos; resultando na ruptura das pontes dissulfeto, decomposição dos lipídios, diminuição da melanina e numerosas lesões micromoleculares. Especificamente, a radiação UVB atinge os pigmentos de melanina, oxidando-os e ocasionando a degradação e branqueamento destes; e as frações da queratina, resultando na quebra das pontes dissulfeto dentro da fibra e na superfície da cutícula. No entanto, a radiação UVA produz espécies reativas de oxigênio (EROs), que são radicais livres que interagem com fotossensibilizadores endógenos. Estas radiações causam efeitos indesejados como a diminuição da hidratação e o aumento da permeabilidade, conduzindo a uma perda de cor e brilho e aumentando a resistência ao pentear. Com isso, a fibra capilar sofre a decomposição devido aos danos à queratina e à fração lipídica ocasionadas pela radiação solar. ${ }^{16,17}$

Com base no gráfico da perda proteica (Figura 2), observa-se que a diferença da perda proteica entre o tratamento com os xampus magistral e comercial é mínima, com uma ligeira maior degradação pelo xampu magistral. Analisando a máxima variabilidade dos resultados (desvios padrão) em cada ciclo, apenas no ciclo 6 é que pode ocorrer uma degradação proteica ligeiramente maior pelo tratamento com o xampu comercial e; examinando a mínima variabilidade, apenas no ciclo 2 pode acontecer uma perda maior pelo xampu comercial.

Entretanto, pela análise estatística dos dados da perda proteica pelo teste t de Student $(a<0,05)$ (Tabela 5) entre 0 tratamento do cabelo com os xampus magistral e comercial, obteve-se uma diferença significativa entre os xampus quanto à perda proteica. 0 cabelo lavado com o xampu magistral apresentou maior perda proteica em relação ao xampu comercial. 
Tabela 5 - Análise estatística dos dados pelo teste $t$ para amostras pareadas.

\begin{tabular}{ccc}
\hline & Xampu magistra & Xampu comercial \\
\hline Média & 0,15276 & 0,13805 \\
Variância & 0,004408 & 0,003531 \\
Observações & 7 & 7 \\
Correlação de Pearson & & 0,99547 \\
Hipótese da diferença de média & 0 & \\
gl & & 6 \\
Stat $t$ & 4,23583 \\
$\mathrm{P}(\mathrm{T}<=\mathrm{t})$ uni-caudal & 0,00273 \\
$\mathrm{t}$ crítico uni-caudal & 1,94318 \\
$\mathrm{P}(\mathrm{T}<=\mathrm{t})$ bi-caudal & 0,00546 \\
$\mathrm{t}$ crítico bi-caudal & 2,44691 \\
\hline
\end{tabular}

O que pode explicar a menor degradação proteica pelo xampu comercial é a sua formulação, o qual possui agentes condicionantes. Um destes agentes presentes é 0 pantenol, uma pró-vitamina que penetra na haste de forma osmótica e se mantém de forma substantiva após o enxágue, ajudando na retenção da umidade e evitando a sensação de ressecamento e fragilidade.18,19 Ainda assim, a diferença observada é mínima, sendo que 0 xampu magistral degradaria em lavagens diárias, anualmente, cerca de apenas $0,5219 \mathrm{mg} / \mathrm{g}$ de cabelo a mais que o xampu comercial.

\section{Conclusão}

Os ensaios de friç̧ão demonstraram que o uso diário de ambas formulações de xampus causa uma perda proteica, sendo que o xampu magistral degrada anualmente 6,4824 mg/g e, o xampu comercial, degrada $5,9605 \mathrm{mg} / \mathrm{g}$ de cabelo. Acredita-se que o xampu comercial degradou menos devido este possuir agentes condicionantes como o pantenol em sua formulação, enquanto que o xampu magistral não continha nenhum destes agentes em sua composição. Consequentemente, a diferença das perdas proteicas foi estatisticamente significativa.

0 presente estudo mostrou também que as formulações de xampus degradam bem menos que o uso de soluções de tensoativos na lavagem dos cabelos, conforme mostrado em outros experimentos, confirmando a importância de outros agentes presentes nas formulações no condicionamento do cabelo.

Diante da diversidade de matérias-primas disponíveis à formulação de xampus e, devido ao crescente aumento do consumo destes produtos no mercado brasileiro, esta metodologia

Saúde (Santa Maria), v.39, n.2, p.109-120, 2013. Avaliação da degradação proteica da fibra capilar por ação de xampus (ensaios de fricção e método BCA) torna-se importante para o desenvolvimento de formulações que produzam menor dano capilar, podendo ser empregada para avaliar diferentes formulações e tipos de cabelo em estudos futuros. 


\section{Referências Bibliográficas}

1. Nakano AK. Comparação dos danos induzidos em cabelos de três etnias por diferentes tratamentos [dissertação]. Campinas: Universidade Estadual de Campinas; 2006.

2. Nogueira ACS. Efeito da radiação ultravioleta na cor, na perda proteica e nas propriedades mecânicas do cabelo [dissertação]. Campinas: Universidade Estadual de Campinas, 2003.

3. Wagner RCC, Joekes I. Hair protein removal by sodium dodecyl sulfate. Colloids Surf B Biointerfaces. 2005;41(1):7-14.

4. Wagner RCC. Degradação do cabelo decorrente do tratamento contínuo com lauril sulfato de sódio e silicone [dissertação]. Campinas: Universidade Estadual de Campinas, 2003.

5. Bhushan B. Nanoscale characterization of human hair and hair conditioners. Prog Mater Sci. 2008;53(4):585-710.

6. Bouillon C. Shampoos and hair conditioners. Clin Dermatol. 1988;6(3):83-92.

7. Aulton ME. Delineamento de formas farmacêuticas. $2^{\mathrm{a}}$ ed. Porto Alegre: Artmed; 2005.

8. Cserháti T, Forgács E, Oros G. Biological activity and environmental impact of anionic surfactants. Environ Int. 2002;28(5):337-48.

9. Curry KV, Golding S. Hair lipids - I. The extraction of fatty materials from hair clippings. J Soc Cosmet Chem. 1971;22(11):681-99.

10. Smith PK, Krohn RI, Hermanson GT, Mallia AK, Gartner FH, Provenzano MD, et al. Measurement of protein using bicinchoninic acid. Anal Biochem. 1985;150(1):76-85.

11. Lowry OH, Rosebrough NJ, Farr AL, Randall RJ. Protein measurement with the Folin phenol reagent. J Biol Chem. 1951;193(1):265-75.

12. Fountoulakis M, Juranville JF, Manneberg M. Comparison of the Coomassie brilliant blue, bicinchoninic acid and Lowry quantitation assays, using non-glycosylated and glycosylated proteins. J Biochem Biophys Methods. 1992;24(3-4):265-74.

13. Keller RP, Neville MC. Determination of total protein in human milk: comparison of methods. Clin Chem. 1986;32(1):120-23.

14. Zaia DAM, Zaia CTB, Lichtig J. Determinação de proteínas totais via espectrofotometria: vantagens e desvantagens dos métodos existentes. Quím Nova. 1998;21(6):787-93.

15. Robbins CR. Chemical and physical behavior and human hair. 4th ed. New York: Springer-Verlag; 2002.

16. Fernández E, Barba C, Alonso C, Martí M, Parra JL, Coderch L. Photodamage determination of human hair. J Photochem Photobiol B. 2012;106:101-06.

17. Fernández E, Martínez-Teipel B, Armengol R, Barba C, Coderch L. Efficacy of antioxidants in human hair. J Photochem Photobiol B. 2012;117:146-56.

18. Idson B. Vitamins and skin. Cosm \& Toil. 1993;108(2):79-94.

19. Paola MVRV, Ribeiro ME, Yamamoto JK. Multifuncionalidade das vitaminas. O poder das vitaminas nos produtos cosméticos. Cosm \& Toil Brasil. 1998;10(4):44-54. 


\section{Camila Helena Ferreira Cuelho}

Endereço para correspondência - Rua Silva Jardim, 2279, ap. 305, Centro, CEP 97100-493, Santa Maria, RS, Brasil.

Currículo Lattes: http://lattes.cnpq.br/9672114876723230

E-mail: camilahfcuelho@gmail.com

Recebido em 28 de março de 2013.

Aprovador em 08 de outubro de 2013. 